\title{
Synthesis, characterization, and experimental investigation of surface activity of SERS substrates using neodymium oxide $\left(\mathrm{Nd}_{2} \mathrm{O}_{3}\right)$
}

\author{
Fatemeh Sadeghi ${ }^{1}$, Farzad Khani ${ }^{2}$, Abbas Hemati Azandaryani ${ }^{3,4}$, Yadollah Mansouri ${ }^{5,6^{*}}$,
}

Zahra Shaykhi Mehrabadi ${ }^{3^{*}}$ and Amir Nikjou ${ }^{1}$

\begin{abstract}
The activity of two surface-enhanced Raman scattering (SERS) substrates was investigated using neodymium oxide $\left(\mathrm{Nd}_{2} \mathrm{O}_{3}\right)$ molecules. Colloidal silver solution, containing nano-sized silver particles and silver-coated filter papers were used as the SERS substrates. In order to characterize the substrates, ultraviolet-visible spectroscopy, dynamic light scattering, and scanning electron microscopy were used. Subsequently, gain enhancement factors were calculated from the measured spectra to monitor the change in effectiveness of the SERS substrates under prolonged storage time. Experimental results show that for enhancing the Raman signal, the activity of two fabricated substrates is very effective.
\end{abstract}

Keywords: Surface-enhanced Raman scattering (SERS), Colloidal silver, Silver-coated filter paper, Neodymium oxide $\left(\mathrm{Nd}_{2} \mathrm{O}_{3}\right)$

\section{Background}

Surface-enhanced Raman scattering (SERS) is a sensitive and selective technique in which Raman scattering enhancing is achieved for those adsorbed molecules on metal nano-sized particles. Using this method, not only for the molecule structure analysis but also the information about the direction of molecule absorption and interaction between the molecule and the substrates can be attained [1-3].

SERS was first observed on absorbed pyridine molecules on the surface of roughed silver electrode with chemical method by Fleischmann et al. [4]. At the beginning, an unusual increase in the intensity of Raman signals was attributed to the growth of roughed substrate area. Then in 1977, Jean Marie and his colleagues found that the growth of the Raman scattering's cross section has another reason than the increase of molecules due to being roughed [5]. Nowadays, there are different ideas

\footnotetext{
* Correspondence: yadollamansouri@yahoo.com; sheikhizahra@yahoo.com ${ }^{5}$ Environmental Epidemiological Research Center, Kermanshah University of Medical Sciences, Kermanshah 6714676573, Iran

${ }^{3}$ Department of Applied Chemistry, Faculty of Chemistry, Razi University, Kermanshah 6715685438, Iran

Full list of author information is available at the end of the article
}

to describe this effect, which two major categories are considering the intensity proportion of Raman scattering with the polarization of molecule and electric field shown as follows.

1. Electromagnetic effect: The mechanism is based on the optical properties of the noble metals and their ability to support plasmon resonances at visible wavelengths.

2. Chemical effect or charge transition: In this condition, the molecule is absorbed chemically by the metal nano-sized particles, and Raman enhancing is due to the exchange of electrons from metal to molecule and their return to the metal.

In other words, the molecule's polarization is affected by the interaction between the molecule and metal's surface. This effect is possible only for the first electronic state of the adsorbed molecule. Another important factor is the selection rules. When a molecule is adsorbed on the gold, silver, or other noble metals, its symmetry is decreased, and this leads to weaken the selection rules. As a result, more frequencies than those in the ordinary Raman spectroscopy are found [6-8]. 


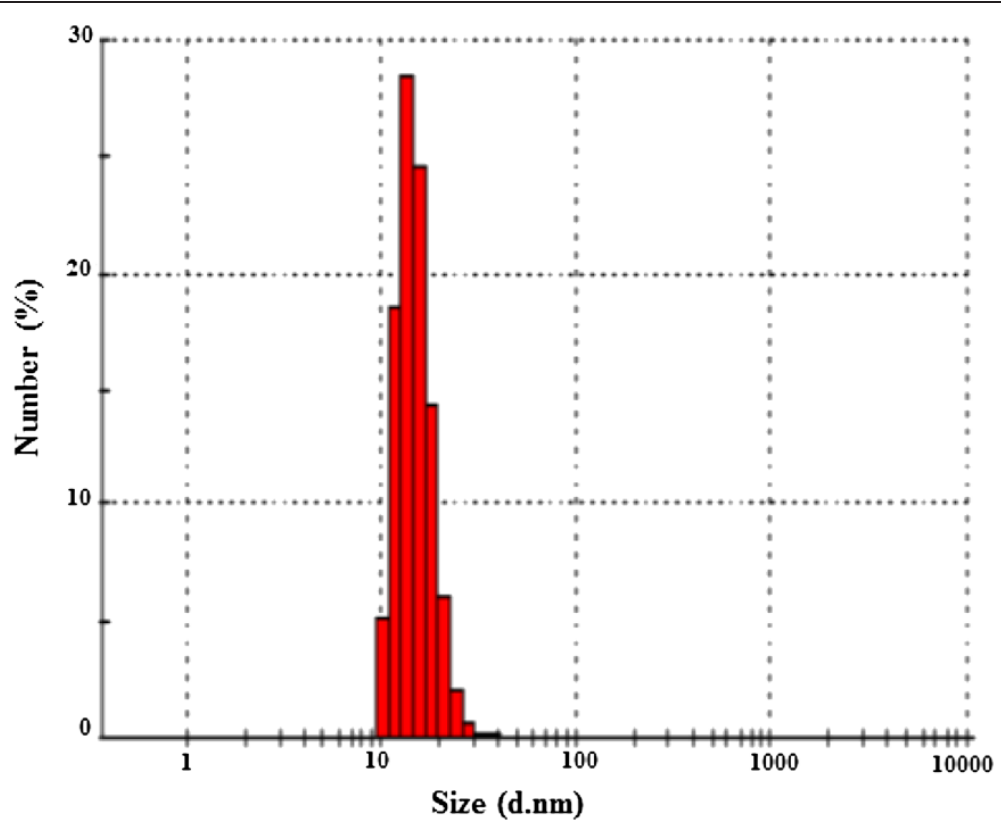

Figure 1 The particle size distribution of a typical prepared sample.

There are different kinds of SERS-active substrates used in the wide range of SERS applications such as metal colloids, coated filter papers with metal nanoparticles, electrochemically roughened metal electrodes, etc. [9-11].

In this study, we report a fabrication of the SERSactive substrate using colloidal silver nanoparticles and then characterized surface activity of SERS substrates by several methods such as scanning electron microscopy (SEM); dynamic light scattering (DLS) was investigated. Also, the plasmon absorption of the formed nanocrystals was monitored by ultraviolet-visible (UV-vis) spectrometry.

\section{Results and discussions}

Zetasizer Nano-Zs by Malvern Instruments (Worcestershire, UK) was used to define the size of the silver nano-sized particles. In this experiment, we dilute the collide solution with proportion of 5:1 using deionized water. Since, by increasing the average of scattering numbers of $\mathrm{N}$, the number of oscillations is declined, and their effects are vanished in the large $\mathrm{N}$ [12]. The distribution of particles size of $\mathrm{Ag}$ metal that was shown in Figure 1 is relatively narrow, and the average particle size is about $16.9 \mathrm{~nm}$.

In order to obtain a scanning electron microscopic image, we used freshly prepared nano-particles and micrographs of the samples (Figure 2). The size of the

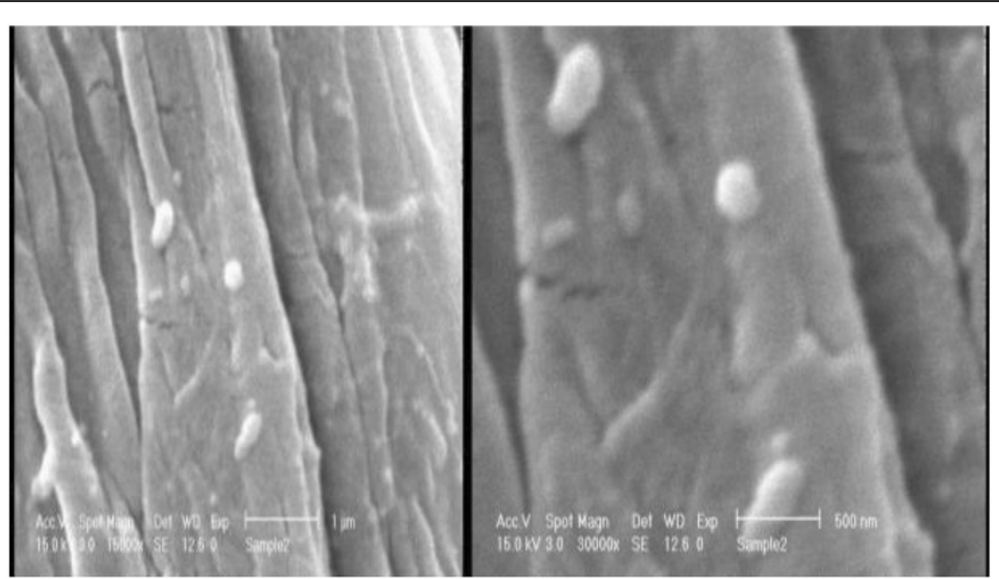

Figure 2 SEM of filter paper coated using nano-particles of silver. 


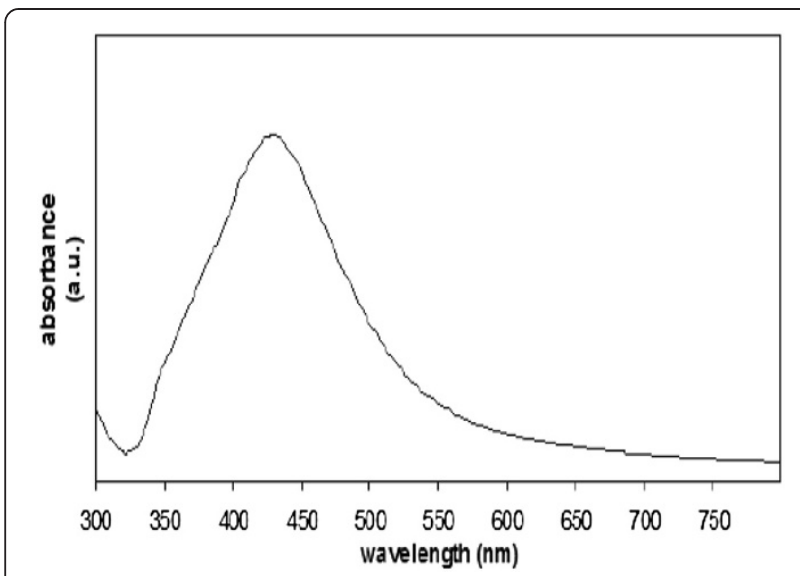

Figure $3 \mathrm{UV} / \mathrm{vis}$ spectrum of the prepared Ag colloidal sample.

nano-sized particles is estimated around 40 to $240 \mathrm{~nm}$ by microstructure measurement. In fact, it is supposed that the larger nano-sized particles are not, silver, perhaps they are salts existing in colloidal silver solution that are recrystallized after drying. Moreover, the micrographs demonstrated a spherical shape and a smooth surface, with a particle size in the nano-metric range $[13,14]$.

Excitation of the localized surface plasmon resonance (LSPR) is characterized by strong, wavelength-selective absorption and enhanced electromagnetic fields at the nano-particle surface. This provides the opportunity to simply follow the optical properties of the nanostructures utilizing UV-vis spectrometry and the tremendous enhancement of the weak Raman signal, respectively.
The maximum SERS enhancement is expected to take place when the max of LSPR is slightly longer than the laser (excitation) wavelength such that both the Raman scattered photon and the incident photon are strongly enhanced [11,15].

Hence, it is possible to adjust the wavelength maximum of the longitudinal resonance plasmon according to the excitation laser wavelength to obtain the largest Raman enhancement [16]. Colloidal silver solution was characterized using UV/vis/near-infrared (NIR) spectrophotometer. Figure 3 showed that the surface plasmon absorption band of colloidal silver was around $430 \mathrm{~nm}$.

In Figure 4, we showed the Raman spectra and SERS of $\mathrm{Nd}_{2} \mathrm{O}_{3}$ molecules using colloidal silver: Figure 4a shows Raman spectrum in $1 \mathrm{M} \mathrm{Nd}_{2} \mathrm{O}_{3}$ solution without using SERS substrates. In Figure 4b, Raman spectrum in $0.01 \mathrm{M} \mathrm{Nd}_{2} \mathrm{O}_{3}$ solutions is shown which has lower density. According to Figure $4 \mathrm{~b}$, the peaks of $\mathrm{Nd}_{2} \mathrm{O}_{3}$ do not appear in this concentration. But in Figure 4c, the SERS spectrum for $0.01 \mathrm{M}$ of $\mathrm{Nd}_{2} \mathrm{O}_{3}$ that was calculated using the colloidal silver shows the peaks of $\mathrm{Nd}_{2} \mathrm{O}_{3}$ even better than in $1 \mathrm{M}$ solution.

Figure 5 depicted the SERS spectrum of $\mathrm{Nd}_{2} \mathrm{O}_{3}$ molecules using filter paper coated with nano-silvers. Figure $5 \mathrm{~b}$ shows that filter paper possesses high enhancing power than colloidal silver although the filter paper does not show some weak peaks. Comparison between the location of the main flow peak and their intensities is shown for both substrates in Table 1. To quantify the degradation in the SERS effectiveness of the silver nanorods affected by the storage time, we calculated the Raman enhancement factor from the SERS spectra as previously

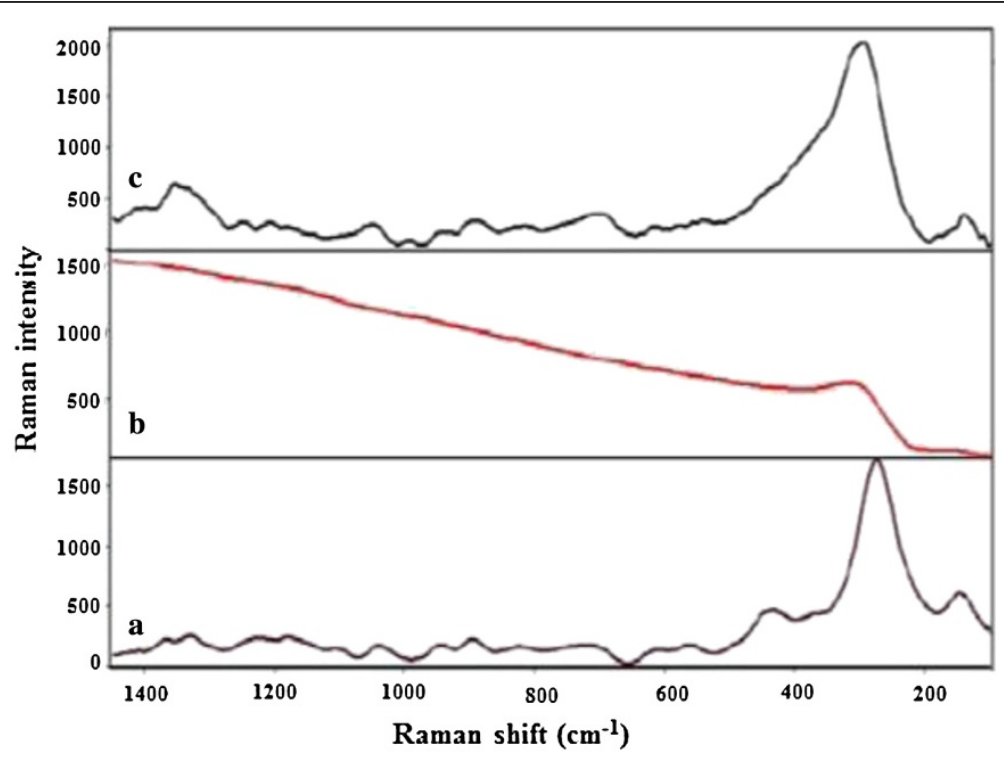

Figure 4 Raman spectra and SERS of $\mathrm{Nd}_{2} \mathrm{O}_{3}$ molecules using colloidal silver. The Raman spectrum of $1 \mathrm{M} \mathrm{Nd}_{2} \mathrm{O}_{3}$ solution (a). The Raman spectrum of $0.01 \mathrm{M} \mathrm{Nd}_{2} \mathrm{O}_{3}$ solution (b). The SERS spectrum of $0.01 \mathrm{M} \mathrm{Nd}_{2} \mathrm{O}_{3}$ by silver colloid (c). 


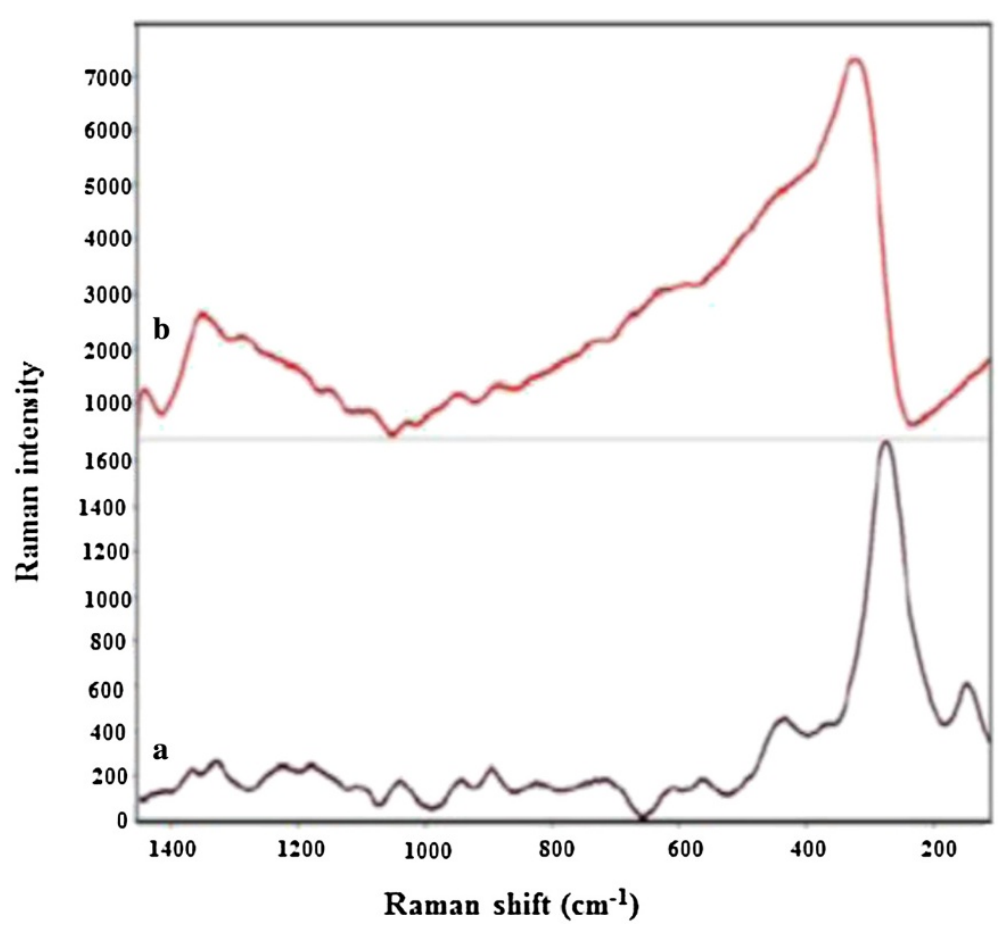

Figure 5 The Raman spectrum and SERS of $\mathrm{Nd}_{2} \mathrm{O}_{3}$ molecules using filter paper. (a) The Raman spectrum of $1 \mathrm{M} \mathrm{Nd}_{2} \mathrm{O}_{3}$ solution and (b) the SERS spectrum of $0.01 \mathrm{M}$ of it using filter paper.

shown. The enhancement factor was defined as the ratio of inelastic scattering intensity per molecule between the presence and absence of the SERS structure. The Raman enhancement factor was calculated by following formula [17]:

$$
E F=\frac{I_{\text {SERS }}}{I_{\text {Raman }}} \times \frac{C_{\text {Raman }}}{C_{\text {SERS }}}
$$

In which, $I$ is the intensity of the peak and $C$ is the concentration or molarity of the solution. We use the selected solution molarity of $C_{\text {SERS }}$. The EF values were shown in Table 1. According to the relatively high enhancement factor (428 for filter paper and 127 for sliver colloidal, the method is practical to detect the molecules with a low concentration and even single molecules.

In addition to Raman enhancing and detecting the molecules with low concentration, we can obtain information about molecule structure of $\mathrm{Nd}_{2} \mathrm{O}_{3}$ and its absorption trait

Table 1 Comparison of the intensities of the main peaks of $\mathrm{Nd}_{2} \mathrm{O}_{3}$ for two substrates

\begin{tabular}{cccc}
\hline Substrate & $\begin{array}{c}\text { Location of the } \\
\text { peak }\left(\mathbf{c m}^{-1}\right)\end{array}$ & $\begin{array}{c}\text { Intensity of } \\
\text { the peak }\end{array}$ & $\begin{array}{c}\text { Enhancement } \\
\text { factor }\end{array}$ \\
\hline Filter paper & 322 & 7,327 & 458 \\
Silver colloid & 294 & 2,026 & 127 \\
$\mathrm{Nd}_{2} \mathrm{O}_{3}$ molecule, 1 & 279 & 1,599 & \\
M solution & & & \\
\hline
\end{tabular}

using SERS effect. The location of Raman and SERS peaks of $\mathrm{Nd}_{2} \mathrm{O}_{3}$ molecules is investigated in Table 2 .

\section{Conclusions}

In this study, SERS was used to characterize colloidal silver solution, containing nano-sized silver particles. The solution was used to make filter paper covered using nano-sized silver. Absorption spectrum of colloidal silver showed the plasmon resonance in 430-nm wavelength

Table 2 The location of Raman and SERS peaks

\begin{tabular}{|c|c|c|c|}
\hline $\begin{array}{c}1 \mathrm{M} \\
\text { solution of } \\
\mathrm{Nd}_{2} \mathrm{O}_{3}\left(\mathrm{~cm}^{-1}\right) \\
\end{array}$ & $\begin{array}{l}0.01 \mathrm{M} \text { solution of } \\
\mathrm{Nd}_{2} \mathrm{O}_{3} \text { in silver } \\
\text { colloid }\left(\mathrm{cm}^{-1}\right)\end{array}$ & $\begin{array}{c}0.01 \mathrm{M} \text { solution of } \\
\mathrm{Nd}_{2} \mathrm{O}_{3} \text { on filter } \\
\text { paper }\left(\mathrm{cm}^{-1}\right)\end{array}$ & Band \\
\hline 147 & 140 & & \\
\hline 274 & 294 & 322 & $\begin{array}{c}\text { Stretching } \\
\text { vibration } \\
\text { Nd-O }\end{array}$ \\
\hline 434 & & & $\begin{array}{c}\text { Stretching } \\
\text { vibration } \\
\mathrm{Nd}_{2} \mathrm{O}_{2}\end{array}$ \\
\hline 592 & & 588 & \\
\hline 721 & 701 & 722 & \\
\hline 896 & 815 & 948 & \\
\hline 1,180 & 1,209 & 1,154 & $\begin{array}{c}\text { Stretching } \\
\text { vibration } \\
\text { O-O }\end{array}$ \\
\hline 1,330 & 1,355 & 1,352 & \\
\hline
\end{tabular}


using UV/vis/NIR. The DLS method also showed that the average size for nano-sized particles in colloid is $16.9 \mathrm{~nm}$. To be certain about the existence of nano-sized silver particles on the filter paper, we used SEM imaging. SEM imaging proves the existence of the nano-sized silver particles on the filter papers, and their size is estimated about 40 to $240 \mathrm{~nm}$. Moreover, the micrographs demonstrated a spherical shape and a smooth surface for particles. SERS spectrum for $\mathrm{Nd}_{2} \mathrm{O}_{3}$ was investigated for both substrates, and a satisfactory enhancement was observed.

\section{Methods}

\section{Preparation of colloidal silver}

Colloidal silver nano-particles were prepared according to Lee and Meisel's method [18]. Briefly, $18 \mathrm{mg}$ of $\mathrm{AgNO}_{3}$ was dissolved in 100-ml distilled water, and the solution was heated to boiling. Then, $7 \mathrm{ml}$ of $1 \%$ trisodium citrate aqueous solution was added into the boiling silver nitrate solution at once, under vigorous stirring. The mixed solution was kept boiling for a further $8 \mathrm{~min}$. Finally, the green-gray solution was obtained which was stable for several days or weeks.

In order to investigate rang of colloidal silver activity, we used $\mathrm{Nd}_{2} \mathrm{O}_{3} \cdot \mathrm{Nd}_{2} \mathrm{O}_{3}$ is used to cover the glass for example in sunglasses, solid-state laser, and colored glasses [19]. To prepare $\mathrm{Nd}_{2} \mathrm{O}_{3}$ using colloidal silver, its molar solution with the proportion of 1:2 was mixed by colloidal silver, and the solution's $\mathrm{pH}$ was altered 8 up to $13[20,21]$. The peaks existing in $1 \mathrm{M}$ solution were observed more clearly in $\mathrm{pH}=12$.

\section{Preparation of the silver-coated filter papers}

The filter paper used in this method has a very low filtration speed (MN 61q de $125 \mathrm{~mm}$ ). We dropped the colloidal silver solution one by one on the filter paper, then let it to dry in the room temperature for about $10 \mathrm{~min}$, and did this action several times. In this way, a group of filter papers covered using different nano-sized silver layers were achieved [22]. Finally, we drop the $0.01 \mathrm{M} \mathrm{Nd}_{2} \mathrm{O}_{3}$ solution drops one by one on the papers and let it to dry in the ordinary temperature.

\section{Structural characterization and SERS detection}

For characterization, the morphology of Ag-NPA-coated substrate was examined by a SEM (JSM-6700F, JEOL Ltd., Akishima-shi, Japan). The surface-enhanced Raman spectra were measured using a microscopic confocal Raman spectrometer (RM 2000, Renishaw, Wottonunder-Edge, UK), employing a Nd-YAG laser as the light source $(=532 \mathrm{~nm})$. The beam diameter was $1 \_\mathrm{m}$, and the integration time for each spectrum was set as $10 \mathrm{~s}$.
Measurement of the hydrodynamic diameter of the nano-particles was accomplished using DLS (Nano ZS4700, Malvern Instruments, Worcestershire, UK). For size measurement, all paper formulations were diluted using deionized water to eliminate the effect of viscosity caused by the ingredients.

\section{Competing interests}

The authors declare that they have no competing interests.

\section{Authors' contributions}

AHA and YM conceived of the study, participated in its design and coordination, and worked on the preparation of nanoparticles, the silvercoated filter papers, and characterization with Zetasizer. FS and FK participated in the design of the study and performed the statistical analysis. ZSM drafted the manuscript, and AN rechecked the whole manuscript. All the authors read and approved the final manuscript.

\section{Acknowledgments}

We acknowledge Kenneth B Pael for his valuable editing of our article.

\section{Author details}

${ }^{1}$ Department of Physics, Payam Noor University, Tehran 19395-4697, Iran. ${ }^{2}$ Department of Mathematics, Razi University, Kermanshah 6715685438, Iran. ${ }^{3}$ Department of Applied Chemistry, Faculty of Chemistry, Razi University, Kermanshah 6715685438, Iran. ${ }^{4}$ Nano Drug Delivery Research Center, Kermanshah University of Medical Sciences, Kermanshah 6714676573, Iran. ${ }^{5}$ Environmental Epidemiological Research Center, Kermanshah University of Medical Sciences, Kermanshah 6714676573, Iran. ${ }^{6}$ Department of Analytical Chemistry, Faculty of Chemistry, Razi University, Kermanshah 6715685438, Iran.

Received: 18 April 2013 Accepted: 22 May 2013

Published: 1 June 2013

\section{References}

1. Zhang, X, Shah, NC, Van Duyne, RP: Sensitive and selective chem/bio sensing based on surfaceenhanced Raman spectroscopy (SERS). Vib. Spectrosc. 42, 2-8 (2006)

2. Wang, LR, Fang, Y: IR-SERS study and theoretical analogue on the adsorption behavior of pyridine carboxylic acid on silver nanoparticles. Spectrochim. Acta Part A 63, 614-618 (2006)

3. Serra, A, Manno, D, Filippo, E, Buccolieri, A, Urso, E, Rizzello, A, Maffia, M: SERS based optical sensor to detect prion protein in neurodegenerate living cells. Sens. Actuators A 156, 479-485 (2011)

4. Fleischmann, M, Hendra, PJ, McQuillan, AJ: Raman spectra of pyridine adsorbed at a silver electrode. Chem. Phys. Lett. 163, 26-33 (1974)

5. Kneipp, K, Moskovits, M, Kneipp, H: Surface-Enhanced Raman Scattering: Physics and Applications. Springer, New York (2006)

6. Aroca, R: Surface-Enhanced Vibrational Spectroscopy. University of Windsor, Ontario, Canada (2006). Chapter 3

7. Smith, E, Dent, G: Modern Raman Spectroscopy-A Practical Approach. John Wiley and Sons, Hoboken (2005)

8. Kosuda, KM, Bingham, JM, Wustholz, KL, Van Duyne, RP: Nanostructures and surface-enhanced Raman spectroscopy. In: Andrews, DL, Scholes, GD, Wiederrecht, GP (eds.) Comprehensive Nanoscience and Technology, vol. 3, pp. 263-301. Academic, Oxford (2011)

9. Vo-Dinh, T: Surface-enhanced Raman spectroscopy using metallic nanostructures trends. Anal. Chem. 17, 8-14 (1998)

10. Le Ru, EC, Etchegoin, PG: Principles of Surface-Enhanced Raman Spectroscopy. Elsevier, Amsterdam (2009)

11. El-Sherbiny, IM, Salih, E, Reicha, FM: Green synthesis of densely dispersed and stable silver nanoparticles using myrrh extract and evaluation of their antibacterial activity. J. Nanostruct. Chem 3(8), 1-7 (2013)

12. Ru, ECL, Blackie, E, Meyer, M, Etchegoin, PG: Surface enhanced Raman Scattering enhancement factors: A comprehensive study. J. Phys. Chem. 111, 13794-13803 (2007)

13. Rukiye, S, Murvet, V: Surface-enhanced Raman scattering (SERS) studies on silver nanorod substrates. Sens. Actuators B 139, 150-155 (2009) 
14. Farhadi, S, Pourzare, $\mathrm{K}$, Sadeghinejad, S: Simple preparation of ferromagnetic $\mathrm{CO}_{3} \mathrm{O}_{4}$ nanoparticles by thermal dissociation of the $\left.\mathrm{Coll}\left(\mathrm{NH}_{3}\right)_{6}\right]\left(\mathrm{NO}_{3}\right)_{2}$ complex at low temperature. J. Nanostruct. Chem 3(16), 1-7 (2013)

15. McFarland, AD, Young, MA, Dieringer, JA, Van Duyne, RP: Wavelength scanned surface-enhanced Raman excitation spectroscopy. J. Phys. Chem. B $109,11279-11285(2005)$

16. Banerji, B, Pramanik, SK, Pal, U, Maiti, NC: Dipeptide derived from benzylcystine forms unbranched nanotubes in aqueous solution. J. Nanostruct. Chem 3(12), 1-6 (2013)

17. Nuntawong, N, Eiamchai, P, Wong-ek, B, Horprathum, M, Limwichean, K, Patthanasettakul, V, Chindaudom, P: Shelf time effect on SERS effectiveness of silver nanorod prepared by OAD technique. Vacuum 88, 23-27 (2013)

18. Lee, PC, Meisel, D: Adsorption and surface-enhanced Raman of dyes on silver and gold. Sols. J. Phys. Chem. 86, 3391-3395 (1982)

19. http://en.wikipedia.org/wiki/ $\mathrm{Nd}_{2} \mathrm{O}_{3}$

20. Jing, C, Fang, Y: Simple method for electrochemical preparation of silver dendrites used as active and stable SERS substrate. J. Colloid Interface Sci. $314,46-52$ (2007)

21. Vidhu, S, Tiwari, B, Tovmachenko, O, Krishna Darbha, G, Hardy, W, Singh, JP: Nonresonance SERS effects of colloidal silvers with different shapes. Chem. Phys. Lett. 446, 77-83 (2007)

22. Niu, Z, Fang, Y: Surface-enhanced Raman scattering of single-walled carbon nanotubes on silver-coated and goldcoated filter paper. J. Colloid Interface Sci. 303, 224-301 (2006)

doi:10.1186/2193-8865-3-40

Cite this article as: Sadeghi et al:: Synthesis, characterization, and experimental investigation of surface activity of SERS substrates using neodymium oxide $\left(\mathrm{Nd}_{2} \mathrm{O}_{3}\right)$. Journal Of Nanostructure in Chemistry 2013 3:40.

\section{Submit your manuscript to a SpringerOpen ${ }^{\circ}$ journal and benefit from:}

- Convenient online submission

- Rigorous peer review

- Immediate publication on acceptance

- Open access: articles freely available online

- High visibility within the field

- Retaining the copyright to your article 